\title{
Effect of variation in the COPD breathing flow pattern on end-tidal CO2 tension: An in vitro study
}

\author{
Cletus F Adams, Mark C Jermy ${ }^{1 *}$, Patrick H Geoghegan ${ }^{2}$ and CJT Spence ${ }^{3}$ \\ ${ }^{1}$ Centre for Bioengineering, Department of Mechanical Engineering, University of Canterbury, New Zealand \\ ${ }^{2}$ Biomedical Engineering, School of Life and Health Sciences, Aston University, Birmingham, UK \\ ${ }^{3}$ Fisher \& Paykel Healthcare, Auckland, New Zealand
}

\begin{abstract} $30 \mathrm{~L} / \mathrm{min}$ of $\mathrm{NHF}$ reduced $\mathrm{EtCO}_{2}$ by approximately $20 \%$. a $2 \%$ rise in $\mathrm{EtCO}_{2}$.

\section{Introduction}

Arterial $\mathrm{CO}_{2}$ tension modulates ventilation via a feedback mechanism. It is thus reasonable to hypothesise that each breathing pattern (though influenced by disease state) is optimized in terms of shape, amplitude and frequency to effect a specific change in $\mathrm{CO}_{2}$ tension. Previous studies have explored how tidal volume, dead space volume, respiratory frequency and metabolic $\mathrm{CO}_{2}$ rate influence $\mathrm{EtCO}_{2}$. In a study by Parot, et al. [1] the respiratory frequency and metabolic $\mathrm{CO}_{2}$ production in hypercapnic and non-hypercapnic COPD patients were found to be similar however the hypercapnic group showed a lower tidal volume. In hypercapnic individuals, the $\mathrm{EtCO}_{2}$ correlates well with the ratio of dead space volume to tidal volume $[2,3]$. $\mathrm{EtCO}_{2}$ has been reported to correlate well with arterial $\mathrm{CO}_{2}$ Tension [4].
\end{abstract}

Aim: The goal of this work was to find out if the variation in breathing flow pattern alone (without change in tidal volume and respiratory rate) changes the end-tidal $\mathrm{CO}_{2}$ tension $\left(\mathrm{EtCO}_{2}\right)$ enough to affect the health of a patient. The influence of $\mathrm{I}: \mathrm{E}$ ratio on $\mathrm{EtCO}_{2}$ was also investigated.

Method: Four breathing flow patterns belonging to different individuals diagnosed with COPD were collected from the literature. These were scaled to the same tidal volume, respiratory rate and I:E ratio, leaving shape as the only varying parameter. A programmable piston pump was used to reproduce the breathing flow patterns in an anatomically correct adult upper airway model (3D printed in acrylic, Visijet Ex200). $\mathrm{CO}_{2}$ was simultaneously bled into the pump chamber at steady rate to mimic metabolic $\mathrm{CO}_{2}$ production, followed by the measurement of $\mathrm{EtCO}_{2}$ with and without $30 \mathrm{~L} / \mathrm{min}$ of nasal high flow therapy.

Results: Breathing flow patterns varying in shape but not in tidal volume, respiratory rate and $\mathrm{I}$ : $\mathrm{E}$ ratio can produce statistically significant differences in $\mathrm{EtCO}_{2}$. The variability in $\mathrm{EtCO}_{2}$ was however found to be small $(1-2 \%)$ and unlikely to be physiologically relevant. A $35 \%$ fall in $\mathrm{I}: \mathrm{E}$ ratio corresponded to a $2 \%$ rise in $\mathrm{EtCO}$.

Conclusion: Shape alone can cause a statistically significant difference in $\mathrm{EtCO}_{2}$ however the difference in $\mathrm{EtCO}_{2}$ is small. A $35 \%$ reduction in $\mathrm{I}: \mathrm{E}$ ratio results in

Critically ill patients suffering from COPD benefit from nasal high flow (NHF) therapy, which is the administration of warmed and humidified air at flow rates up to $8 \mathrm{~L} / \mathrm{min}$ in neonates [5-7] and 60 $\mathrm{L} / \mathrm{min}$ in adults [8]. NHF reduces the physiological dead space and respiratory frequency, and improves gas exchange [9-12].

The capnogram of a COPD patient is modulated by the degree of obstruction of the airways [13-15]. This obstruction, which affects the breathing flow pattern and magnitude, causes the capnogram of COPD patients to have a 'shark fin shape', [16] making them distinct from those of healthy individuals, which are more rectangular in shape [17]. Clinical studies on how a variation in the breathing flow pattern alone change $\mathrm{EtCO}_{2}$ are scarce due to the difficulty in simultaneously maintaining the same tidal volume, peak airflow and I:E ratio over several breaths. In this report, an in-vitro study of the effect of breathing flow pattern, with and without NHF, on $\mathrm{EtCO}_{2}$ is presented. Also the influence of $\mathrm{I}$ :E ratio variation on $\mathrm{EtCO}_{2}$ is explored.

\section{Methodology}

\section{Waveform collection}

Four breathing flow patterns obtained from COPD patients (age range $=17-77$ years, FEV $1 \%$ pred $=36-63 \%$ ) were collected from the literature. In three of these flow patterns [18-20], flow rate was plotted against time. In the remainder [21], the flow pattern was presented as a plot of tidal volume versus time which was numerically integrated to yield flow rate versus time plot after acquisition. Together with a healthy adult breathing flow waveform, which was previously used by Van Hove, et al. [22] and Spence, et al. [23] five waveforms were used in all.

A plot of all the waveforms collected is shown in Figure 1a. Note that positive flow represent inspiration and negative flow, expiration. The four COPD waveforms are designated as WF1, WF2, WF3 and WF4 with the healthy waveform labelled as WF5 (unmarked solid line). The COPD flow waveforms have a sharp concavity in the expiratory phase. It is noticeable that they vary in frequency and amplitude.

\section{Normalization of waveforms}

All the waveforms were normalized to the same tidal volume and respiratory rate via a linear rescaling of time axis followed by a

Correspondence to: Mark C. Jermy, Centre for Bioengineering, Department of Mechanical Engineering, University of Canterbury, New Zealand, E-mail: mark. jermy@canterbury.ac.nz

Key words: end-tidal CO2 tension, nasal high flow therapy

Received: October 01, 2017; Accepted: October 17, 2017; Published: October 19, 2017 
linear rescaling of the flow rate axis using different scaling factors for inspiratory and expiratory phases. Also, the inspired volume was matched to the expired volume. Two groups of breathing flow waveforms were obtained by scaling each breathing flow to two different I:E ratios i.e. 0.67 (IE1-group) and 0.43 (IE2-group), which corresponded to inspiratory time fractions of $40 \%$ and $30 \%$. The fall in I:E ratio from 0.67 to 0.43 equals $35 \%$. This change of $35 \%$ in I:E ratio was hypothesized to be sufficient to produce a significant change in $\mathrm{EtCO}_{2}$. The breathing flow patterns

in the IE1-group and IE2-group are shown in Figures $1 \mathrm{~b}$ and $1 \mathrm{c}$ respectively. Two different I:E ratios were needed to investigate the effect of I:E ratio on $\mathrm{EtCO}_{2}$. The choice of I:E ratios were not without justification as Tobin, et al. [24] reported an I:E ratio of $0.73 \pm 0.03$ for healthy adults and $0.53 \pm 0.05$ for adult COPD patients.

\section{Experimental setup}

The experimental set-up is shown in Figure 2b. In the setup, a rigid upper airway model (3D-printed in acrylic, Visijet EX200) - Figure 2a - of an anonymous 44 year male adult (previously used by Spence, et al. [25] and Van Hove, et al. [22]) was connected to a piston pump. $\mathrm{A} \mathrm{CO}_{2}$ source was connected to the barrel of the piston pump via a rotameter. $\mathrm{CO}_{2}$ was sampled at the trachea using a $20 \mathrm{~Hz}$ capnograph (MiniMediCO ${ }_{2}$, manufactured by Oridion Medical Ltd., Israel). A mixing test conducted by placing a wire-gauze (to enhance mixing) at the entrance of the piston pump yielded no significant difference in $\mathrm{EtCO}_{2}(< \pm 3 \%)$. The volume of the piston chamber at the end of expiration (functional residual capacity) was maintained at $2500 \mathrm{ml}$ for all experiments.

\section{Experimental procedure}

The pump forces the tracheal flow rate to follow the healthy waveform (WF5) in Figure $1 \mathrm{~b}$ and Figure 1c. Metabolic $\mathrm{CO}_{2}$ production was simulated by bleeding $\mathrm{CO}_{2}$ at a flow rate of $98 \mathrm{scc} / \mathrm{min}$ (at a 20 $\mathrm{KPa} \mathrm{CO}_{2}$ source pressure) into the barrel of the piston pump. The endtidal $\left(\mathrm{EtCO}_{2}\right)$ at this setting was $5.4 \% \pm 0.3$, which is comparable to the $\mathrm{EtCO}_{2}$ of a resting healthy adult. $\mathrm{CO}_{2}$ data was recorded before (zerotherapy, ZT) and during the application of $30 \mathrm{~L} / \mathrm{min}$ of NHF (NHF30). An identical procedure was performed for all other waveforms with 6 repetitions for each.

\section{Results}

The capnogram was recorded for 20 consecutive breathing cycles for each experimental repeat. The 20 cycles of capnogram in repeat one (for healthy waveform (WF5) in IE1-group) have been superimposed and cascaded with those of the other repetitions as shown in Figure 3a. The variations in $\mathrm{EtCO}_{2}$ from cycle to cycle is due to mixing. Figure $3 \mathrm{~b}$ shows the average of all 120 capnograms ( 20 cycles in each of the 6 repeats) for WF5 (in IE1-group) with and without NHF. An identical plot is shown in Figure 3c for WF4 (a COPD waveform). Note the characteristic 'shark fin' shape of the COPD waveform (which is due to airway obstruction) [16]

The spontaneous breathing plots (for a no NHF condition) in Figure $3 \mathrm{~b}$ and Figure $3 \mathrm{c}$ show a minimum $\mathrm{CO}_{2}$ concentration of about $0.2 \%$ which is due to rebreathing of dead space $\mathrm{CO}_{2}$ during inspiration. Note how this falls to $0.04 \%$ (atmospheric $\mathrm{CO}_{2}$ concentration) when $\mathrm{NHF}$ of $30 \mathrm{~L} / \mathrm{min}$ is applied. This indicates a reduction in re-inspired dead space $\mathrm{CO}_{2}$ by NHF, which is in line with findings by Spence, et al. [23] and Van Hove, et al. [22] that NHF promotes mixing and flushes dead space $\mathrm{CO}_{2}$. In Figure $3 \mathrm{~b}$ and Figure $3 \mathrm{c}$ the $\mathrm{EtCO}_{2}$ falls by approximately $20 \%$ when NHF of $30 \mathrm{~L} / \mathrm{min}$ is applied.
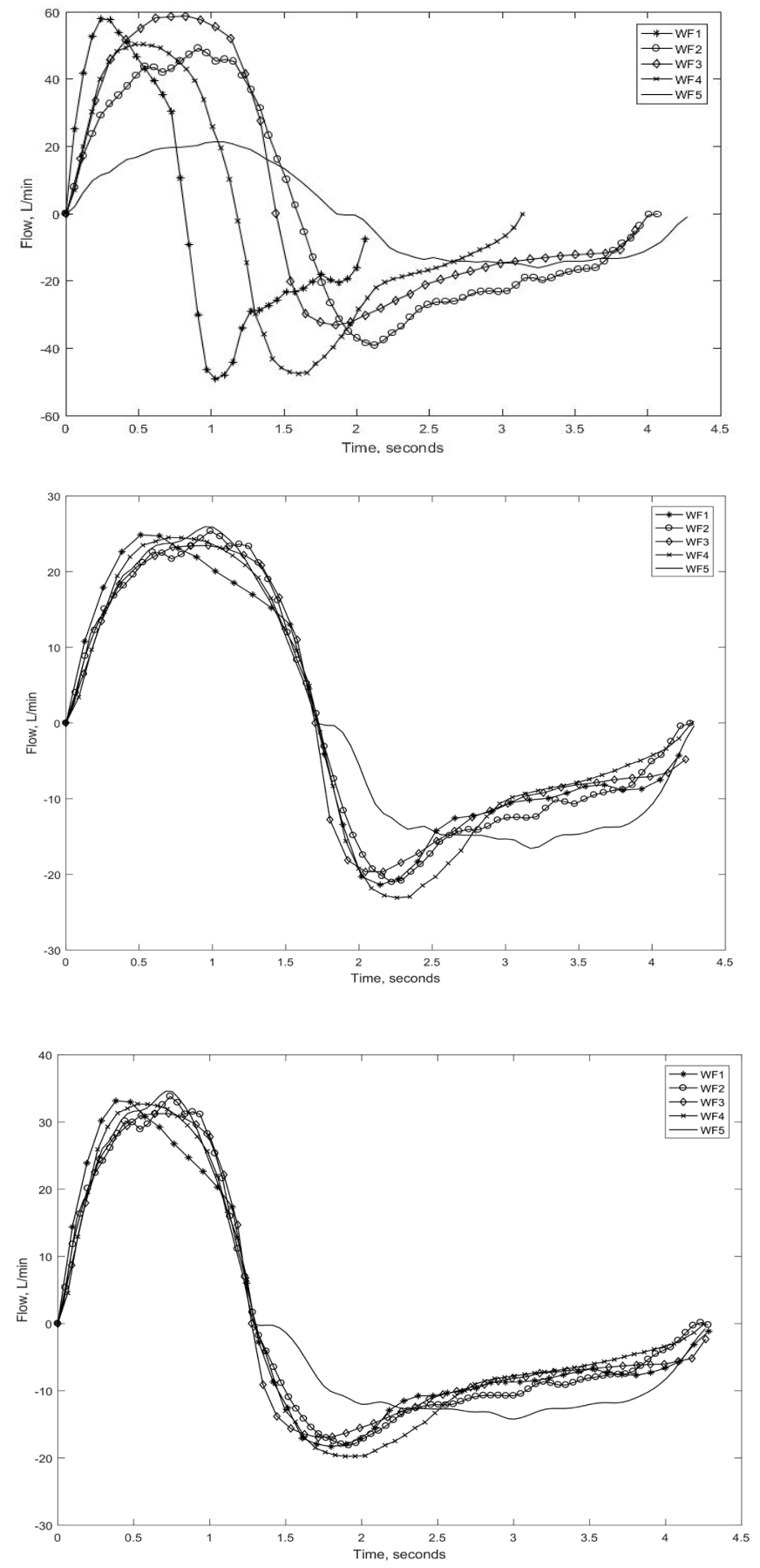

Figure 1. (a) All waveforms before scaling (b) IE1-group of flow waveforms (c) IE2-group of flow waveforms.

The average $\mathrm{EtCO}_{2}$ (of 120 capnograms) for each waveforms (in both IE1-group and IE2-group) have been presented in Figure 4. The error bars represent two standard deviations in $\mathrm{EtCO}_{2}$. In Figure 4, the $\mathrm{EtCO}_{2}$ vary slightly between waveforms (e.g. see IE1-group waveforms) however the error bars overlap. Also pairs of plots belonging to the same waveform show some difference in $\mathrm{EtCO}_{2}$ though error bars overlap (e.g. for label WF4 in Figure 4, compare the IE1-group and IE2-group pair).

The present finding shows that the characteristic shape of the COPD capnogram ('shark fin') - due to airway obstruction - can be 


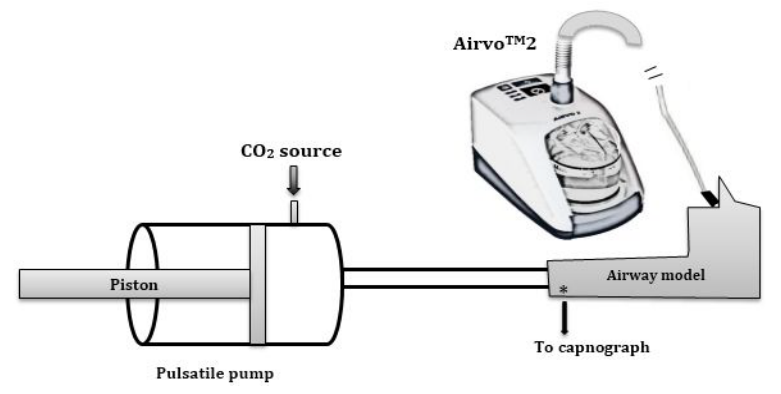

Figure 2. (a) Upper airway model (b) UAM is connected to the piston pump and $\mathrm{AIRVO}^{\mathrm{TM}} 2$ device. $\mathrm{CO}_{2}$ source is connected to piston pump for simulation of metabolic $\mathrm{CO}_{2}$ production. $\mathrm{CO}_{2}$ is sampled at the trachea during experiment.
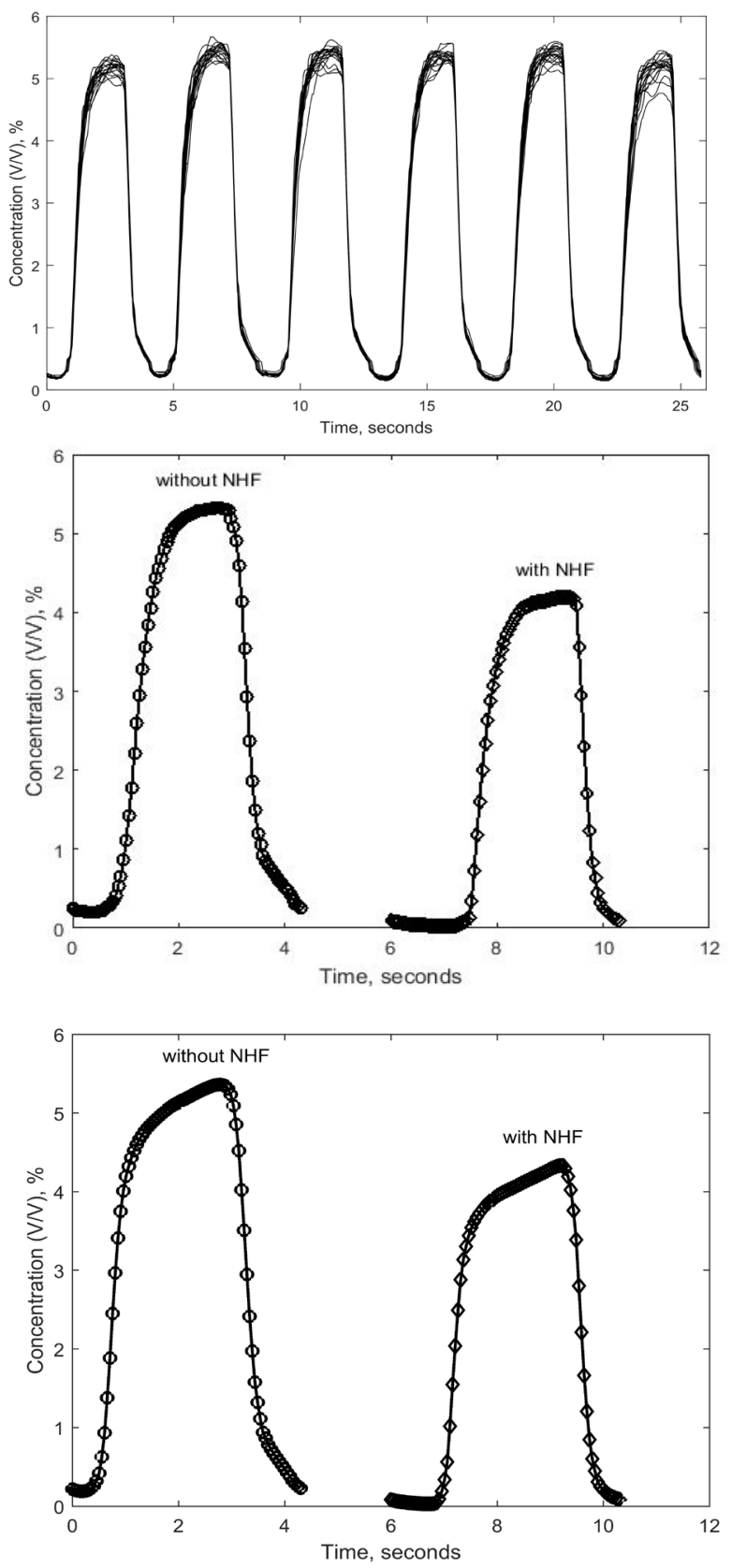

Figure 3. (a) A train of 6 capnograms for the healthy waveform (WF5) (b) Average of 120 capnograms for WF5 (c) Average of 120 capnograms for WF4.

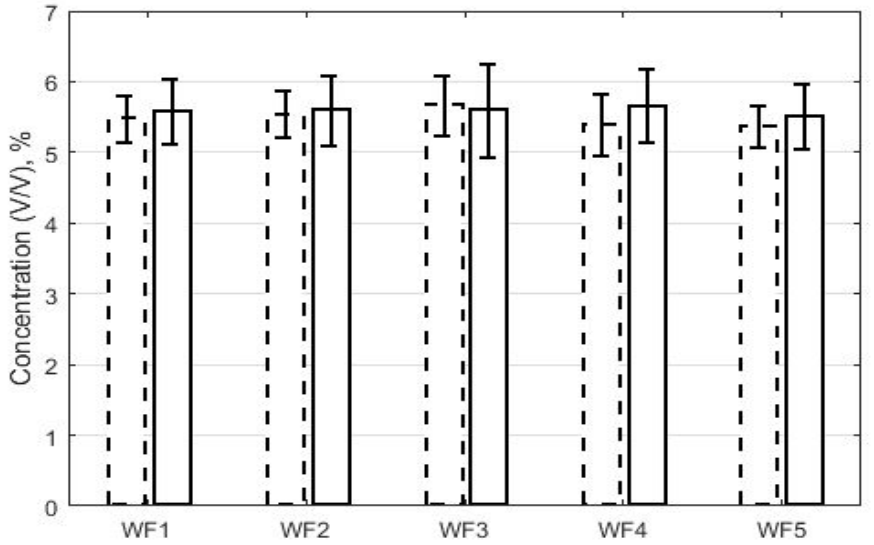

Figure 4. A plot of the average $\mathrm{EtCO}_{2}$ of 120 capnograms associated with flow waveforms in both groups (IE1-group and IE2-group). The errorbars represent two standard deviations in $\mathrm{EtCO}_{2}$ over the 120 capnograms.

reproduced from the corresponding breathing flow pattern. This supports the clinical reports that the breathing flow pattern modifies the shape of the capnogram [16]. Though error bar overlaps in $\mathrm{EtCO}_{2}$ have been observed between and within the I:E ratio groups (IE- 1 and IE-2) it is not conclusive if this means no statistically significant difference in $\mathrm{EtCO}_{2}$ exists. In what follows a test of statistical difference in $\mathrm{EtCO}_{2}$ is performed.

\section{Test of statistical significance}

A single factor ANOVA test was performed to find if the difference in $\mathrm{EtCO}_{2}$ was statistically significant between different waveforms of the same I:E ratio. Further, a two sample t-test (assuming unequal variances) on pairs of $\mathrm{EtCO}_{2}$ belonging to the same waveform but differing in I:E ratio was performed. In both tests, the critical value to confirm the null hypothesis was set to 0.02 instead of 0.05 to indicate a strong evidence against the null hypothesis. The results are presented in Table I, which shows evidence of statistically significant difference in $\mathrm{EtCO}_{2}$ (p-value $<0.02$ ) within the same group of I:E ratio (single factor ANOVA test, Table 1). Except for WF4, I:E ratio made a statistically significant difference in $\mathrm{EtCO}_{2}$ ( $\mathrm{p}$-value $<0.02$ ) in pairs belonging to the same I:E ratio (two-sample t-test, Table I). WF4 was not distinct in characteristics from the other waveforms.

Another two-sample t-test was performed for each I:E ratio group to find the specific pairings of flow waveforms that showed statistically significant difference in $\mathrm{EtCO}_{2}$ as the single factor ANOVA test could not determine this. Note that 5 flow waveforms will yield 10 pairs. The results are presented in Table 2 in which 7 pairs (70\%) - in bold ink show statistically significant difference in $\mathrm{EtCO}_{2}$ (p-value $<0.02$ ) within the IE1-group. Only 4 pairs (40\%) in the IE2 group have statistically significant differences in $\mathrm{EtCO}_{2}$.

It is concluded that the differences in $\mathrm{EtCO}_{2}$ of waveforms that are similar in all but pattern are statistically significant (p-value $<0.02)(a$ single factor ANOVA test, Table I). Also, $\mathrm{EtCO}_{2}$ is sensitive to I:E ratio as 4 out of 5 flow waveforms (WF1, WF2, WF3 and WF5 but not WF4) showed a statistically significant difference in $\mathrm{EtCO}_{2}$ (p-value $<0.02$ ) (two sample t-test, Table 1). Furthermore, it is deduced from Table 2 that though statistically significant disparities in $\mathrm{EtCO}_{2}$ was found in each group (Table 1), intragroup differences in $\mathrm{EtCO}_{2}$ in the higher I:E ratio group (IE1-group, I:E ratio $=0.67$ ) were more frequent $(70 \%)$ than in the lower I:E ratio group (IE2-group, I:E ration $=0.47$ ) - only $40 \%$ of the pairs showed a significant difference in $\mathrm{EtCO}_{2}$. 
Table 1. Results of a single factor ANOVA test and a two-sample t-test. A single factor ANOVA Test.

\begin{tabular}{|c|c|c|c|c|c|}
\hline Groups & Sum of & \multirow{2}{*}{ df } & Mean & \multirow{2}{*}{ F } & P-value \\
\cline { 1 - 2 } (IE1 and IE2) & squares & & square & & \\
\hline IE1 & 259 & 4 & 65 & 20 & 0.0001 \\
\hline IE2 & 84 & 4 & 21 & 5 & 0.0006 \\
\hline \multicolumn{7}{|r|}{} & Two-sample t-Test \\
\hline & WF1 & WF2 & WF3 & WF4 & WF5 \\
\hline p-value & 0.003 & 0.0001 & 0.002 & 0.05 & 0.002 \\
\hline
\end{tabular}

Table 2. My caption.

\begin{tabular}{|c|c|c|c|c|c|}
\hline \multirow{2}{*}{ p-value } & WF1/ & WF1/ & WF1/ & WF1/ & WF2/ \\
\cline { 2 - 6 } & WF2 & WF3 & WF4 & WF5 & WF3 \\
\hline IE1 & 0.068 & 0 & 0.048 & 0.017 & 0 \\
\hline IE2 & 0.03 & 0.105 & 0 & 0 & 0.32 \\
\hline \multirow{2}{*}{ p-value } & WF2/ & WF2/ & WF3/ & WF3/ & WF4/ \\
\cline { 2 - 6 } & WF4 & WF5 & WF4 & WF5 & WF5 \\
\hline IE1 & 0.08 & 0 & 0 & 0 & 0 \\
\hline IE2 & 0.036 & 0.031 & 0.015 & 0.013 & 0.49 \\
\hline
\end{tabular}

\section{Shape parameter and $\mathrm{EtCO}_{2}$}

Harmonic distortion $(H d)$ describes the degree to which a periodic signal deviates from a sinusoid [26]. It is mathematically expressed as:

$$
H d=\frac{\sqrt{H_{2}^{2}+H_{3}^{2}+H_{4}^{2}+\ldots}}{H_{1}}
$$

where $H_{\mathrm{n}}$ is the root-mean-square amplitude of the $\mathrm{n}^{\text {th }}$ harmonic (found using Fourier decomposition) of the waveform. $\mathrm{n}=25$ was used as beyond this, changes in $H d$ was found to be insignificant. $H d$ was computed for the entire breathing cycle, for the inspiratory phase and then the expiratory phase. $\mathrm{EtCO}_{2}$ correlated better with a product of the inspiratory $H d$ and the peak inspiratory flow. This product is designated as IDf. The $\mathrm{EtCO}_{2}$ and their corresponding IDf are presented in Figure 5. The Spearman's correlation coefficient $(\rho)$ and error (2 standard deviations) in the measurement of $\mathrm{EtCO}_{2}$ are also shown in Figure 5. The coefficient of determination (R2) ( 0.75 and 0.88$)$ and $\rho$ (0.9 and 1) indicate a strong correlation between IDf and $\mathrm{EtCO}_{2}$ (Figure 5). It is not clear what implication this has for breathing.

In Equation 2, average[EtCO2] $]_{I E 2}$ and average[EtCO2] $]_{I E 1}$ are respectively, the average $\mathrm{EtCO}_{2}$ in the IE1-group and IE2-group. Using the formula in Equation 2 the average $\mathrm{EtCO}_{2}$ of the IE2-group was found to be $2 \%$ greater than that of the IE1-group. It is concluded that a $35 \%$ fall in I:E ratio (percentage difference between the I:E ratio of 0.67 (IE1-group) and 0.43 (IE2-group)) produces a $2 \%$ rise in $\mathrm{EtCO}_{2}$.

$$
\frac{\text { average }\left[\mathrm{EtCO}_{2}\right]_{I E 2}-\text { average }\left[\mathrm{EtCO}_{2}\right]_{I E 1}}{\text { average }\left[\mathrm{EtCO} \mathrm{I}_{2 \mathrm{I} 1}\right.}
$$

The coefficient of variability, defined as the ratio of the standard deviation in $\mathrm{EtCO}_{2}$ within the group to the average $\mathrm{EtCO}_{2}$ was found to be $2 \%$ and $1 \%$ respectively for the IE1-group and IE2-group.

\section{Discussion}

NHF reduces physiological dead space, respiratory frequency, and improves gas exchange [9-11]. The fall in $\mathrm{EtCO}_{2}(\approx 20 \%)$ upon the application of $30 \mathrm{~L} / \mathrm{min}$ of NHF supports the report that NHF improves mixing and reduces the proportion of $\mathrm{CO}_{2}$ in re-inspired dead space air $[9,22,23]$. The present data suggests that breathing flow waveforms of different patterns, but similar in tidal volume, period and I:E ratio show statistically significant differences in $\mathrm{EtCO}_{2}$. Further, the results indicate that two breathing waveforms that differ only in I:E ratio can produce different $\mathrm{EtCO}_{2}$. If that tidal volume and respiratory rate are fixed, it is more probable to find a statistically significant difference in $\mathrm{EtCO}_{2}$ between a greater I:E ratio group than those of a lower I:E ratio.

To preserve tidal volume, a fall in I:E ratio (longer expiration, shorter inspiration) is matched by a rise in peak inspiratory breathing flow and a fall in peak expiratory breathing flow. In Figure 4, the $\mathrm{EtCO}_{2}$ corresponding to the lower I:E ratio i.e. 0.46 (IE2-group) tended to be greater. Tobin, et al. [24] observed that the inspiratory time (Ti) of 28 COPD subjects (mean age $=67.5$ years) was 1 second less than that of healthy adults. Sorli, et al. [27] concluded that $\mathrm{CO}_{2}$ retention (marked by higher $\mathrm{EtCO}_{2}$ ) in COPD patients is due to shallow breathing, which arises from reduced $\mathrm{Ti}$. This suggests the higher $\mathrm{EtCO}_{2}$ is due to less efficient purging of the dead space during inspiration, i.e. lower ratio of inspired volume to dead space volume resulting in less complete replacement of dead space gas with fresh air (residual volume of expired gas mixes with a smaller volume of fresh gas). This is in unison with the observation by Gorini, et al. [28] who found the highest arterial partial pressure of $\mathrm{CO}_{2}$ amongst COPD patients with the smallest $\mathrm{Ti}$. IE1-group and IE2-group differed in Ti by 0.43 seconds. In the present data, a fall in I:E ratio by $35 \%$ ( 0.67 to 0.43 ) corresponded to $2 \%$ rise in $\mathrm{EtCO}_{2}$. Though the present results agrees qualitatively with findings in the literature $[24,27,28]$ it is concluded that the fall in $\mathrm{EtCO}_{2}$ due to a fall in I:E ratio by $35 \%$ is small (2\%). The variability in $\mathrm{EtCO}_{2}$ due to flow pattern difference is $1-2 \%$. Though statistically significant, it is also small.

The product of inspiratory flow and inspiratory harmonic distortion (IDf) correlate well with $\mathrm{EtCO}_{2}$. The expiratory breathing flow has been reported to be modulated by the inspiratory flow pattern [26]. Inspiratory muscle dysfunction increases $\mathrm{EtCO}_{2}$. Begin, et al. [29] found that airway resistance correlated well with arterial $\mathrm{CO}_{2}$ tension, which also correlates well with $\mathrm{EtCO}_{2}$ [30]. In a study by Loveridge, et al. [31] healthy subjects were observed to show a greater variability in breathing pattern than COPD subjects. Since airway obstruction during COPD influences $\mathrm{EtCO}_{2}$ and the flow pattern, it is speculated that $I D f$ is related to the ventilatory response to $\mathrm{CO}_{2}$ tension.

\section{Limitations of this work}

The piston chamber is rigid, unlike the human lung which is compliant (lung compliance is $\approx 200 \mathrm{~mL} / \mathrm{cmH}_{2} \mathrm{O}$ for healthy young adults). Note that a constant bleed rate differs from the physiologically realistic system in which $\mathrm{CO}_{2}$ flow is distributed over time. Also, this work is limited by the number of breathing flow patterns used.

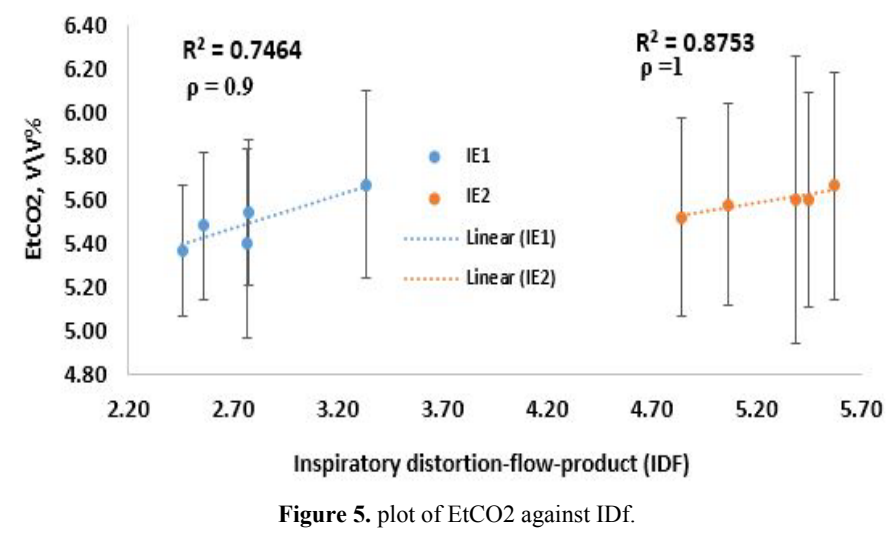




\section{Conclusion}

Breathing patterns similar in tidal volume, respiratory rate, and I:E ratio but differing in shape can produce statistically significant difference in $\mathrm{EtCO}_{2}$ however the variability is small (1 - 2\%). A 35\% fall in I:E ratio of breathing waveforms with no change in tidal volume and respiratory rate produces only a $2 \%$ rise in $\mathrm{EtCO}_{2}$. NHF of $30 \mathrm{~L} / \mathrm{min}$ reduces $\mathrm{EtCO}_{2}$ by $20 \%$.

\section{Acknowledgment}

The authors would like to thank the University of Canterbury for a Doctoral Scholarship, Fisher \& Paykel Healthcare for the loan of equipment and advice, and MBIE Smart Ideas grant UOAX1403.

\section{References}

1. Parot S, Saunier C, Gautier H, Milic-Emili J, Sadoul P (1980) Breathing pattern and hypercapnia in patients with obstructive pulmonary disease. American Review of Respiratory Disease 121: 985-991.

2. Calverley PMA (2003) Respiratory failure in chronic obstructive pulmonary disease. European Respiratory Journal 22: 26s-30s.

3. Blanch L, Romero PV, Lucangelo U (2006) Volumetric capnography in the mechanically ventilated patient. Minerva Anestesiol 72: 577-586. [Crossref]

4. Nagler J, Krauss B (2009) Capnographic monitoring in respiratory emergencies. Clinical Pediatric Emergency Medicine 10: 82-89.

5. Manley BJ, Owen LS, Doyle LW, Andersen CC, Cartwright DW, et al. (2013) Highflow nasal cannulae in very preterm infants after extubation. $N$ Engl J Med 369: 14251433. [Crossref]

6. Motojima Y, Ito M, Oka S, Uchiyama A, Tamura M, et al. (2016) Use of high-flow nasal cannula in neonates: Nationwide survey in Japan. Pediatr Int 58: 308-310. [Crossref]

7. Ojha S, Gridley E, Dorling J (2013) Use of heated humidified high-flow nasal cannula oxygen in neonates: a UK wide survey. Acta Paediatr 102: 249-253. [Crossref]

8. Ward JJ (2013) High-flow oxygen administration by nasal cannula for adult and perinatal patients. Respir Care 58: 98-122. [Crossref]

9. Dysart K, Miller TL, Wolfson MR, Shaffer TH (2009) Research in high flow therapy: mechanisms of action. Respir Med 103: 1400-1405. [Crossref]

10. Riera J, Pérez P, Cortés J, Roca O, Masclans JR, et al. (2013) Effect of high-flow nasal cannula and body position on end-expiratory lung volume: a cohort study using electrical impedance tomography. Respir Care 58: 589-596. [Crossref]

11. Mündel T, Feng S, Tatkov S, Schneider H (2013) Mechanisms of nasal high flow on ventilation during wakefulness and sleep. J Appl Physiol (1985) 114: 1058-1065. [Crossref]

12. Sztrymf B, Messika J, Bertrand F, Hurel D, Leon R, et al. (2011) Beneficial effects of humidified high flow nasal oxygen in critical care patients: a prospective pilot study. Intensive Care Med 37: 1780-1786. [Crossref]

13. You B, Peslin R, Duvivier C, Vu VD, Grilliat JP (1994) Expiratory capnography in asthma: evaluation of various shape indices. Eur Respir J 7: 318-323. [Crossref]
14. Krauss B, Hess DR (2007) Capnography for procedural sedation and analgesia in the emergency department. Ann Emerg Med 50: 172-181. [Crossref]

15. Gluncic TJ, Basara L, Konecki L, Tomic S, Samarzija M, et al. (2015) Capnographic measurement as a screening method for respiratory obstructive diseases. European Respiratory Journal 46: 1039.

16. Mieloszyk RJ, Verghese GC, Deitch K, Cooney B, Khalid A, et al. (2014) Automated quantitative analysis of capnogram shape for COPD-normal and COPD-CHF classification. IEEE Trans Biomed Eng 61: 2882-2890. [Crossref]

17. Jaffe $\mathrm{MB}$ (2006) Volumetric capnography, the next advance in $\mathrm{CO}_{2}$ monitoring. Respironics Inc (Critical Care).

18. Colasanti RL, Morris MJ, Madgwick RG, Sutton L, Williams EM (2004) Analysis of tidal breathing profiles in cystic fibrosis and COPD. Chest 125: 901-908. [Crossref]

19. Williams EM, Powell T, Eriksen M, Neill P, Colasanti R (2014) A pilot study quantifying the shape of tidal breathing waveforms using centroids in health and COPD. J Clin Monit Comput 28: 67-74. [Crossref]

20. Dellacà RL, Santus P, Aliverti A, Stevenson N, Centanni S, et al. (2004) Detection of expiratory flow limitation in COPD using the forced oscillation technique. European Respiratory Journal 23: 232-240.

21. Dellacà RL, Pompilio PP, Walker PP, Duffy N, Pedotti A, et al. (2009) Effect of bronchodilation on expiratory flow limitation and resting lung mechanics in COPD. Eur Respir J 33: 1329-1337. [Crossref]

22. Van Hove SC, Storey J, Adams C, Dey K, Geoghegan PH, et al. (2016) An experimental and numerical investigation of $\mathrm{CO} 2$ distribution in the upper airways during nasal high flow therapy. Ann Biomed Eng 44: 3007-3019. [Crossref]

23. Spence CJT, Buchmann NA, Jermy MC (2012) Unsteady flow in the nasal cavity with high flow therapy measured by stereoscopic PIV. Experiments in Fluids 52: 569-579.

24. Tobin MJ, Chadha TS, Jenouri G, Birch SJ, Gazeroglu HB, Sackner MA (1983) Breathing patterns. 2. diseased subjects. Chest 84: 286-294. [Crossref]

25. Spence CJT, Buchmann NA, Jermy MC, Moore SM (2011) Stereoscopic PIV measurements of flow in the nasal cavity with high flow therapy. Experiments in Fluids 50: 1005-1017.

26. Frey U, Silverman M, Suki B (2001) Analysis of the harmonic content of the tidal flow waveforms in infants. J Appl Physiol (1985) 91: 1687-1693. [Crossref]

27. Sorli J, Grassino A, Lorange G, Milic-Emili J (1978) Control of breathing in patients with chronic obstructive lung disease. Clin Sci Mol Med 54: 295-304. [Crossref]

28. Gorini M, Misuri G, Corrado A, Duranti R, Iandelli I, et al. (1996) Breathing pattern and carbon dioxide retention in severe chronic obstructive pulmonary disease. Thorax 51: 677-683. [Crossref]

29. Begin P, Grassino A (1991) Inspiratory muscle dysfunction and chronic hypercapnia in chronic obstructive pulmonary disease. Am Rev Respir Dis 143: 905-912. [Crossref]

30. McSwain SD, Hamel DS, Smith PB, Gentile MA, Srinivasan S, et al. (2010) Endtidal and arterial carbon dioxide measurements correlate across all levels of physiologic dead space. Respir Care 55: 288-293. [Crossref]

31. Loveridge B, West P, Anthonisen NR, Kryger MH (1984) Breathing patterns in patients with chronic obstructive pulmonary disease. Am Rev Respir Dis 130: 730-733. [Crossref]

Copyright: (C2017 Adams CF. This is an open-access article distributed under the terms of the Creative Commons Attribution License, which permits unrestricted use, distribution, and reproduction in any medium, provided the original author and source are credited. 